\title{
Clinical guideline for homeless and vulnerably housed people, and people with lived homelessness experience
}

\author{
Kevin Pottie MD MClSc, Claire E. Kendall MD PhD, Tim Aubry PhD, Olivia Magwood MPH, \\ Anne Andermann MD DPhil, Ginetta Salvalaggio MD MSc, David Ponka MDCM MSc, Gary Bloch MD, \\ Vanessa Brcic MD, Eric Agbata MPH MSc, Kednapa Thavorn PhD, Terry Hannigan, Andrew Bond MD, \\ Susan Crouse MD, Ritika Goel MD, Esther Shoemaker PhD, Jean Zhuo Jing Wang BHSc, Sebastian Mott MSW, \\ Harneel Kaur BHSc, Christine Mathew MSc, Syeda Shanza Hashmi BA, Ammar Saad, Thomas Piggott MD, \\ Neil Arya MD, Nicole Kozloff MD, Michaela Beder MD, Dale Guenter MD MPH, Wendy Muckle BScN MHA, \\ Stephen Hwang MD, Vicky Stergiopoulos MD, Peter Tugwell MD
}

Cite as: CMAJ 2020 March 9;192:E240-54. doi: 10.1503/cmaj.190777

CMAJ Podcasts: author interview at https://soundcloud.com/cmajpodcasts/190777-guide

See related article at www.cmaj.ca/lookup/doi/10.1503/cmaj.200199

$\mathrm{H}$ omeless and vulnerably housed populations are heterogeneous ${ }^{1}$ and continue to grow in numbers in urban and rural settings as forces of urbanization collide with gentrification and austerity policies. ${ }^{2}$ Collectively, they face dangerous living conditions and marginalization within health care systems. ${ }^{3}$ However, providers can improve the health of people who are homeless or vulnerably housed, most powerfully by following evidence-based initial steps, and working with communities and adopting anti-oppressive practices. ${ }^{1,4,5}$

Broadly speaking, "homelessness" encompasses all individuals without stable, permanent and acceptable housing, or lacking the immediate prospect, means and ability of acquiring it. ${ }^{6}$ Under such conditions, individuals and families face intersecting social, mental and physical health risks that significantly increase morbidity and mortality. ${ }^{7,8}$ For example, people who are homeless and vulnerably housed experience a significantly higher prevalence of trauma, mental health conditions and substance use disorders than the general population. ${ }^{7,9}$ Canadian research reports that people who experience homelessness face life expectancies as low as 42 years for men and 52 years for women. ${ }^{7}$

A generation ago, homeless Canadians were largely middleaged, single men in large urban settings. ${ }^{10}$ Today, the epidemiology has shifted to include higher proportions of women, youth, Indigenous people (Box 1), immigrants, older adults and people from rural communities. ${ }^{13,14}$ For example, family homelessness (and therefore homelessness among dependent children and youth) is a substantial, yet hidden, part of the crisis. ${ }^{15}$ In 2014, of the estimated 235000 homeless people in Canada, $27.3 \%$ were women, $18.7 \%$ were youth, $6 \%$ were recent immigrants or migrants, and a growing number were veterans and seniors. ${ }^{10}$

\section{KEY POINTS}

- Clinical assessment and care of homeless and vulnerably housed populations should include tailoring approaches to a person's gender, age, Indigenous heritage, ethnicity and history of trauma; and advocacy for comprehensive primary health care.

- As initial steps in the care of homeless and vulnerably housed populations, permanent supportive housing is strongly recommended, and income assistance is also recommended.

- Case-management interventions, with access to psychiatric support, are recommended as an initial step to support primary care and to address existing mental health, substance use and other morbidities.

- Harm-reduction interventions, such as supervised consumption facilities, and access to pharmacologic agents for opioid use disorder, such as opioid agonist treatment, are recommended for people who use substances.

Practice navigators, peer-support workers and primary care providers are well placed to identify social causes of poor health and provide orientation to patient medical homes. ${ }^{16,17} \mathrm{~A}$ patient's medical home is "a family practice defined by its patients as the place they feel most comfortable presenting and discussing their personal and family health and medical concerns." 18 Medical care is "readily accessible, centred on the patients' needs, provided throughout every stage of life, and seamlessly integrated with other services in the health care system and the community" (https://patientsmedicalhome.ca). Primary care providers are also well positioned to mobilize health promotion, disease prevention, diagnosis and treatment, and rehabilitation services. ${ }^{19}$ 


\section{Box 1: Indigenous homelessness}

Indigenous homelessness is a term used to describe First Nations, Métis and Inuit individuals, families or communities who lack stable, permanent and appropriate housing, or the immediate prospects, means or ability to acquire such housing. However, this term must be interpreted through an Indigenous lens to understand the factors contributing to this condition. These factors include individuals, families and communities isolated from their relationships to land, water, place, family, kin, each other, animals, cultures, languages and identities as well as the legacy of colonialism and genocide. ${ }^{11}$ It is estimated that urban Indigenous people are 8 times more likely to experience homelessness than the general population. ${ }^{11,12}$
However, the social and health resources available to homeless and vulnerably housed people may vary based on geographic setting, municipal resources, housing coordination, and patients' mental health and substance use-related care needs. In addition, many physical and mental health disorders remain undiagnosed or inconsistently treated because of missed opportunities for care, patient mistrust of the health care system or limited access to health services. ${ }^{3}$

Homeless and vulnerably housed people can benefit from timely and effective health, addiction and social interventions. Our guideline provides initial steps for practice, policy and future research, and is intended to build collaboration among clinicians, public health providers and allied health providers. Values such as trauma-informed and patient-centred care, and dignity are needed to foster trust and develop sustainable therapeutic relationships with homeless and vulnerably housed people..$^{20,21}$

\section{Scope}

The purpose of this clinical practice guideline is to inform providers and community organizations of the initial priority steps and effective interventions for homeless and vulnerably housed people. The guideline addresses upstream social and health needs (i.e., housing), as well as downstream health-related consequences of inadequate housing. The target audiences are health providers, policymakers, public health practitioners and researchers.

Our guideline does not aim to address all conditions associated with homelessness, nor does it aim to discuss in depth the many etiologies of homelessness, such as childhood trauma, the housing market, or the root causes of low social assistance rates and economic inequality. Rather, this guideline aims to reframe providers' approach toward upstream interventions that can prevent, treat and work toward ending the morbidity and mortality associated with homelessness.

A parallel set of Indigenous-specific clinical guidelines is currently being developed by an independent, Indigenous-led team. ${ }^{22}$ This process recognizes the distinct rights of Indigenous Peoples, including the right to develop and strengthen their own economies, social and political institutions; the direct links between historic and ongoing colonial policies and Indigenous homelessness; and the need for Indigenous leadership and participation in research that is about Indigenous Peoples.

\section{Recommendations}

The steering committee and guideline panel members developed and approved recommendations to improve social and health outcomes for homeless and vulnerably housed people. The order of these recommendations highlights priority steps for homeless health care. We list a summary of the recommendations in Table 1 and we present our list of good practice statements in Table 2. These good practice statements are based on indirect evidence and support the delivery of the recommendations.

The methods used to develop the recommendations are described later in this document. A summary of how to use this guideline is available in Box 2.

\section{Permanent supportive housing}

- Identify homelessness or housing vulnerability and willingness to consider housing interventions.

- Ensure access of homeless or vulnerably housed individuals to local housing coordinator or case manager (i.e., call 211 or via a social worker) for immediate link to permanent supportive housing and/or coordinated access system (moderate certainty, strong recommendation).

\section{Evidence summary}

Our systematic review (Tim Aubry, University of Ottawa, Ottawa, Ont.: unpublished data, 2020) identified 14 trials on permanent supportive housing (PSH). ${ }^{30-43}$ Several trials across Canada and the United States showed that PSH initiatives house participants more rapidly compared with usual services (73 v. 220 d; adjusted absolute difference 146.4 , 95\% confidence interval [Cl] 118.0 to 174.9$) ;{ }^{30}$ increase the number of people who maintain stable housing at 2 years (pooled odds ratio [OR] 3.58, 95\% Cl 2.36 to 5.43 ); 30,40 and significantly increase the percentage of days spent stably housed. ${ }^{41}$ No trials showed a significant improvement in mental health symptoms compared with standard care. ${ }^{30,31,33,34,41,42}$ Two studies found that the mental health of PSH participants did not improve as much as that of usual care participants (e.g., mean difference $-0.49,95 \% \mathrm{Cl}-0.85$ to -0.12$).{ }^{30,31}$

The At Home/Chez Soi trial showed small improvements in quality of life for high-needs (adjusted standardized mean difference 0.15, $95 \% \mathrm{Cl} 0.04$ to 0.24 ) ${ }^{30}$ and moderate-needs (mean difference 4.37, $95 \% \mathrm{Cl} 1.60$ to 7.14 ) homeless participants in patients receiving $\mathrm{PSH}^{41}$ Youth receiving PSH saw larger improvements in their quality of life during the first 6 months (mean difference 9.30, 95\% Cl 1.35 to 17.24), which diminished over time (mean difference $7.29,95 \% \mathrm{Cl}-1.61$ to 16.18). ${ }^{44}$ No trials showed a significant improvement in substance use compared with standard care..$^{30,33,41-43}$ Most trials reported no effect of PSH on acute care outcomes (e.g., number of emergency department visits and percentage of participants admitted to hospital). ${ }^{30,41} \mathrm{How}$ ever, 2 trials suggest that PSH participants had lower rates of hospital admission (rate reductions of $29 \%, 95 \% \mathrm{Cl} 10$ to 44 ) and time in hospital (e.g., mean difference $-31,95 \% \mathrm{Cl}-48$ to -14$) .34,38,45$ One trial found no effect of PSH on job tenure, hours of work per week or hourly wage compared with standard care. ${ }^{46}$ Participants receiving PSH may have increased odds of employment, but this depends on the severity of participant needs. ${ }^{46}$ One trial found no effect on income outcomes. ${ }^{46}$ 
Table 1: Summary of evidence-based recommendations

\section{Recommendations and clinical considerations}

Recommendation 1: A homeless or vulnerably housed person

- Identify homelessness or housing vulnerability and willingness to consider housing interventions.

- Ensure access for homeless or vulnerably housed individuals to local housing coordinator or case manager (i.e., call 211 or via a social worker) for immediate link to permanent supportive housing and coordinated access system. Clinical considerations: Many jurisdictions will provide alternative housing services for specific marginalized populations, for example, Indigenous people, women and families, youth, those who identify as LGBTQ2+, those with disabilities, refugees and migrants.

Recommendation 2: A homeless or vulnerably housed person with experience of poverty, income instability or living in a low-income household

- Identify income insecurity.

- Assist individuals with income insecurity to identify income-support resources and access income.

Clinical considerations: Consult poverty screening tools when needed (e.g., https://cep.health/clinical-products /poverty-a-clinical-tool-for-primary-care-providers).

Recommendation 3: A homeless or vulnerably housed person with multiple comorbid or complex health needs (including mental illness and/or substance use)

- Identify history of severe mental illness, such as psychotic or mood and anxiety disorders, associated with substantial disability, substance use, or multiple/complex health needs.

- Ensure access to local community mental health programs, psychiatric services for assessment, and linkage to intensive case management, assertive community treatment or critical time intervention where available.

Clinical considerations: Call 211 or consult primary care providers, social workers or case managers familiar with local access points and less intensive community mental health programs.

Recommendation 4: $A$ homeless or vulnerably housed person currently using opioids

- Identify opioid use disorder.

- Ensure access within primary care or via an addiction specialist to opioid agonist therapy (OAT), potentially in collaboration with a public health or community health centre for linkage to pharmacologic interventions.

Clinical considerations: Encourage all patients taking opioid medication to have a naloxone kit. Though barriers to prescribing methadone and buprenorphine remain, be aware of new regulations that aim to facilitate OAT access and options in your jurisdiction, in particular for buprenorphine.

Recommendation 5: A homeless or vulnerably housed person with substance use disorder

- Identify, during history or physical examination, problematic substance use, including alcohol or other drugs.

- Identify the most appropriate approach, or refer to local addiction and harm-reduction/prevention services (e.g., supervised consumption facilities, managed alcohol programs) via appropriate local resources such as public health or community health centre or local community services centre.

Clinical considerations: In case of active opioid use disorder, facilitate patient access to OAT. Patients should be made aware of supervised consumption facility locations (Appendix 1, available at www.cmaj.ca/lookup/suppl/ doi:10.1503/cmaj.190777/-/DC1).

\section{Grade rating*}

Moderate certainty $\oplus \oplus \oplus \mathrm{O}$

Strong recommendation

Low certainty

$\oplus \oplus \circ \bigcirc$

Conditional recommendation

Low certainty

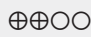

Conditional recommendation

Very low certainty $\oplus \circ \circ \bigcirc$

Conditional recommendation

Very low certainty $\oplus \circ \circ \bigcirc$

Conditional recommendation

Note: LGBTQ2+ = lesbian, gay, bisexual, transgender, questioning and two-spirited.

*See Box 2 for definitions.

†211 is a special abbreviated telephone number reserved in Canada and the United States as an easy-to-remember 3-digit telephone number meant to provide information and referrals to health, human and social service organizations.

The certainty of the evidence was rated moderate, because blinding of participants and personnel was not feasible in any of the trials we examined as a result of the nature of the intervention. Furthermore, several trials did not employ allocation concealment or blinding of outcome-assessment procedures, which could introduce high risks of detection and performance biases.

\section{Income assistance}

- Identify income insecurity.

- Assist individuals with income insecurity to identify incomesupport resources and access income (low certainty, conditional recommendation).

\section{Evidence summary}

We identified 10 trials on income-assistance interventions, including rental assistance, ${ }^{47-56}$ financial empowerment ${ }^{47}$ social enterprise interventions, ${ }^{48}$ individual placement and support, ${ }^{48,54}$ and compensated work therapy. ${ }^{52}$ Our systematic review showed the benefit that income-assistance interventions have on housing stability (Gary Bloch, University of Toronto, Toronto, Ont., and Vanessa Brcic, University of British Columbia, Vancouver, BC: unpublished data, 2020).

Rental assistance increased the likelihood of being stably housed (OR $4.60,95 \% \mathrm{Cl} 3.10$ to 6.83 ). ${ }^{56}$ Rental assistance combined with case management increased the number of days in stable housing per 90-day period compared with case management alone (mean 
Table 2: Good practice statements to support delivery of care

Indirect

evidence

Good practice statement (rence)

1. Homeless and vulnerably housed populations should receive trauma-informed and personcentred care.

2. Homeless and vulnerably housed populations should be linked to comprehensive primary care to facilitate the management of multiple health and social needs.

3. Providers should collaborate with public health and community organizations to ensure programs are accessible and resources appropriate to meet local patient needs.

\section{Box 2: How to use and understand this GRADE guideline} (www.gradeworkinggroup.org)

This guideline supplies providers with evidence for decisions concerning interventions to improve health and social outcomes for people who are homeless or vulnerably housed. This guideline is not meant to replace clinical judgment. Statements about clinical considerations, values and preferences are integral parts of the recommendations meant to facilitate interpretation and implementation of the guideline. Recommendations in this guideline are categorized according to the Grading of Recommendations Assessment, Development and Evaluation (GRADE) system as strong or conditional recommendations.

Strong recommendations indicate that all or almost all fully informed patients would choose the recommended course of action, and indicate to clinicians that the recommendation is appropriate for all or almost all individuals. Strong recommendations represent candidates for quality-of-care criteria or performance indicators.

Conditional recommendations indicate that most informed patients would choose the suggested course of action, but an appreciable minority would not. With conditional recommendations, clinicians should recognize that different choices will be appropriate for individual patients, and they should help patients arrive at a decision consistent with their values and preferences. Conditional recommendations should not be used as a basis for standards of practice (other than to mandate shared decision-making)

Good practice statements represent common-sense practice, are supported by indirect evidence and are associated with assumed large net benefit.

Clinical considerations provide practical suggestions to support implementation of the GRADE recommendation.

\section{GRADE certainty ratings}

High: further research is very unlikely to change our confidence in the estimate of effect.

Moderate: further research is likely to have an important impact on the confidence in the estimate of effect and may change the estimate.

Low: further research is very likely to have an important impact on our confidence in the estimate of effect and is likely to change the estimate.

Very low: any estimate of the effect is very uncertain.

difference 8.58, $p$ < 0.004). ${ }^{55}$ Compensated work therapy was found to reduce the odds of homelessness (OR $0.1,95 \% \mathrm{Cl} 0.1$ to 0.3 ). ${ }^{52}$ No income interventions showed an effect on mental health outcomes. ${ }^{47,52,55,56}$

The impact of these interventions on substance use outcomes were mixed. Provision of housing vouchers did not affect substance use over 3 years; ${ }^{55}$ however, compensated work therapy showed immediate reductions in drug (reduction: $-44.7 \%$, standard error [SE] $12.8 \% ; p=0.001)$ and alcohol use problems (-45.4\%, SE 9.4\%; $p=$ $0.001)$, as well as the number of substance use-related physical symptoms $(-64.4 \%$, SE 8.0\%; $p=0.001) .{ }^{52}$ These differences, however, tended to decline with time. No significant effects were found on overall quality-of-life, finances, health and social relations scores.

Provision of housing vouchers resulted in higher family-relations score and satisfaction, and quality of housing compared with standard care..$^{55}$ One trial reported that rental assistance was associated with reduced emergency department visits and time spent in hospital, but this reduction was not significantly different than in the comparator group. ${ }^{56}$ Individual placement and support was found to improve employment rates only when there was high fidelity to the model (OR 2.42, 95\% Cl 1.13 to 5.16). ${ }^{54}$ Financial-empowerment education and provision of housing vouchers had no effect on employment outcomes. ${ }^{47,55}$ Financial-empowerment education and individual placement and support had no effect on hourly wages. ${ }^{47,54}$ Provision of housing vouchers had no effect on monthly income. ${ }^{55}$

The certainty of the evidence was rated low because several trials introduced high risk of detection and performance bias. Furthermore, 1 trial reported low consent rates of $47 \%$ and a $1: 4$ sampling ratio that further limited statistical power. ${ }^{52}$ As well, participants in the control group wanting to enter income-assistance programs after completing the study had incentives to underreport symptoms, which introduced high risk for measurement bias.

\section{Case management}

- Identify history of severe mental illness, such as psychotic or mood and anxiety disorders, associated with substantial disability, substance use disorders, or multiple or complex health needs.

- Ensure access to local community mental health programs, psychiatric services for assessment and linkage to intensive case management, assertive community treatment or critical time intervention where available (low certainty, conditional recommendation).

\section{Evidence summary}

Our systematic review examined the effectiveness of standard case management, as well as specific intensive casemanagement interventions, such as assertive community treatment, intensive case management and critical time intervention among homeless and vulnerably housed populations and corresponding level of need (David Ponka, University of Ottawa, Ottawa, Ont.: unpublished data, 2020). We included a total of 56 citations, of which 10 trials reported on standard case management, ${ }^{51,57-65} 8$ trials on assertive community treatment, ${ }^{66-73}$ 16 trials on intensive case management ${ }^{74-89}$ and 5 trials on critical time intervention. ${ }^{90-94}$ 
Of 10 trials on standard case management, 10 evaluated housing stability. Only 3 reported significant decreases in homelessness, ${ }^{57,62,63}$ an effect that diminished over time in 1 trial of a time-limited residential case management in which participants in all groups accessed substantial levels of services..$^{57} \mathrm{~A}$ program tailored to women reduced the odds of depression at 3 months (OR $0.38,95 \% \mathrm{Cl} 0.14$ to 0.99 ), but did not show improvements in the women's overall mental health status (mean difference 4.50, $95 \% \mathrm{Cl}-0.98$ to 9.98$).{ }^{64}$ One trial reported higher levels of hostility $(p<0.001)$ and depression symptoms $(p<0.05)$ among female participants receiving nurse-led standard case management compared with those receiving standard care. ${ }^{60}$ Few studies reported on substance use, quality of life, employment or income outcomes.

Findings of assertive community treatment on housingstability, quality-of-life and hospital-admission outcomes are mixed. Two trials found that participants receiving the treatment reported fewer days homeless $(p<0.01)^{71}$ and more days in community housing $(p=0.006),{ }^{70}$ whereas 2 trials reported no effect on episodes of homelessness or number of days homeless. ${ }^{66,73}$ Further, these interventions showed an added benefit in reducing the number of participants admitted to hospital (mean difference $-8.6, p<0.05$ ) and with visits to the emergency department (mean difference $-1.2, p=0.009) .{ }^{67}$ Most trials of assertive community treatment reported no significant differences in mental health outcomes, including psychiatric symptoms, substance use, or income-related outcomes between the treatment and control groups.

Intensive case management reduced the number of days homeless (pooled standardized mean difference $-0.22,95 \% \mathrm{Cl}$ -0.40 to -0.03 ), but not the number of days spent in stable housing. ${ }^{78,80,89}$ In most studies, there was no major improvement in psychological symptoms between the treatment and control groups. However, 1 trial reported significantly greater reductions in anxiety, depression and thought disturbances after 24 months (mean difference change from baseline $-0.32, p=0.007$ ), as well as improved life satisfaction (mean difference $1.23, p=0.001$ ) using intensive case management. ${ }^{86}$ One trial reported no significant difference in quality of life..$^{83}$ Findings on substance use were mixed. Six of the 10 trials reported that intensive case management was associated with improvements in substance use behaviours. ${ }^{74,78,82,84,87,88}$ Participants receiving intensive case management reported fewer visits to the emergency department (mean difference 19\%, $p<0.05$ ) but did not have shorter hospital stays compared with control groups. ${ }^{85}$ Intensive case management had no effect on the number of days of employment, or on income received from employment; however, income received by participants through public assistance increased (e.g., mean difference $89,95 \% \mathrm{Cl} 8$ to 170$).^{78,85}$

Critical time intervention was beneficial in reducing the number of homeless nights (mean difference -591, $p<0.001$ ) and the odds of homelessness (OR $0.23,95 \% \mathrm{Cl} 0.06$ to 0.90 ) during the final 18 weeks of follow-up. ${ }^{91}$ Participants receiving the treatment were rehoused sooner than those receiving standard care, ${ }^{95}$ but did not spend more days rehoused. ${ }^{90}$ Adults receiving critical time intervention showed significant improvements in psychological symptoms (mean difference $-0.14,95 \% \mathrm{Cl}-0.29$ to 0.01)..$^{90}$ However, findings for children's mental health were mixed: children aged $1.5-5$ years showed improvements in internalizing ( $\beta$ coefficient $-3.65,95 \% \mathrm{Cl}-5.61$ to -1.68 ) and externalizing behaviours ( $\beta$ coefficient $-3.12,95 \% \mathrm{Cl}-5.37$ to -0.86 ), whereas changes for children aged $6-10$ years and $11-16$ years were not significant. ${ }^{93}$ There were no significant effects of critical time intervention on substance-use, ${ }^{90}$ quality-of-life ${ }^{90,92}$ or income-related outcomes. ${ }^{96}$ Two trials reported mixed findings on hospital admission outcomes; in 1 study, allocation to critical time intervention was associated with reduced odds of hospital admission (OR $0.11,95 \% \mathrm{Cl} 0.01$ to 0.96 ) and total number of nights in hospital $(p<0.05)$ in the final 18 weeks of the trial. ${ }^{97}$ However, another study reported a greater total number of nights in hospital for the treatment group compared with usual care (1171 v. 912)..$^{98}$

The certainty of the evidence was rated low because several trials introduced high risk of detection and performance bias.

\section{Opioid agonist therapy}

- Identify opioid use disorder.

- Ensure access to opioid agonist therapy in primary care or by referral to an addiction specialist, potentially in collaboration with public health or community health centre for linkage to pharmacologic interventions (low certainty, conditional recommendation).

\section{Evidence summary}

We conducted a review of systematic reviews on pharmalogic interventions for opioid use disorder. ${ }^{99}$ Twenty-four reviews, which included 352 unique primary studies, reported on pharmacologic interventions for opioid use disorder among general populations. ${ }^{100-123}$ We expanded our inclusion criteria to general populations, aware that most studies among "general populations" had a large representation of homeless populations in their samples. We did not identify any substantial reason to believe that the mechanisms of action of our interventions of interest would differ between homeless populations who use substances and the general population of people who use substances. Reviews on pharmacologic interventions reported on the use of methadone, buprenorphine, diacetylmorphine (heroin), levo- $\alpha$-acetylmethadol, slow-release oral morphine and hydromorphone for treatment of opioid use disorder.

We found pooled all-cause mortality rates of 36.1 and 11.3 per 1000 person years for participants out of and in methadone maintenance therapy, respectively (rate ratio $3.20,95 \% \mathrm{Cl} 2.65$ to 3.86), and mortality rates of 9.5 per 1000 person years for those not receiving buprenorphine maintenance therapy compared with 4.3 per 1000 person years among those receiving the therapy (rate ratio $2.20,95 \% \mathrm{Cl} 1.34$ to 3.61). ${ }^{116}$ Overdose-specific mortality rates were similarly affected, with pooled overdose mortality rates of 12.7 and 2.6 per 1000 person years for participants out of and in methadone maintenance therapy, and rates of 4.6 and 1.4 per 1000 person years out of and in buprenorphine maintenance therapy. ${ }^{116}$ Compared with nonpharmacologic approaches, methadone maintenance therapy had no significant 
effect on mortality (relative risk $0.48,95 \% \mathrm{Cl} 0.10$ to 2.39 ). ${ }^{110}$ With respect to morbidity, pharmacologic interventions for opioid use disorder reduced the risk of hepatitis $\mathrm{C}$ virus ( $\mathrm{HCV}$ ) acquisition (risk ratio $0.50,95 \% \mathrm{Cl} 0.40$ to 0.63 ) ${ }^{112}$ and HIV infection. ${ }^{103}$

Adverse events were reported for all agents. ${ }^{100,109,119,122}$ Treatment with methadone and buprenorphine was associated with reduced illicit opioid use (standardized mean difference -1.17 , $95 \% \mathrm{Cl}-1.85$ to -0.49$).{ }^{109}$ Availability of buprenorphine treatment expanded access to treatment for patients unlikely to enrol in methadone clinics and facilitated earlier access for recent initiates to opioid use. ${ }^{117}$ The relative superiority of one pharmacologic agent over another on retention outcomes remains unclear; however, use of methadone was found to show better benefits than nonpharmacologic interventions for retention (risk ratio $4.44,95 \% \mathrm{Cl} 3.26$ to 6.04$).{ }^{110}$

The certainty of evidence ranged from very low to moderate, primarily because of inconsistency, high risk of bias and evidence from nonrandomized studies.

\section{Harm-reduction interventions}

- Identify problematic substance use, including alcohol or other drugs.

- Identify the most appropriate approach or refer to local addiction and harm reduction/prevention services (e.g., supervised consumption facilities, managed alcohol programs) via appropriate local resources, such as public health or community health centre or les centres locaux de services communautaires (low certainty, conditional recommendation).

\section{Evidence summary}

We conducted a review of systematic reviews on supervised consumption facilities and managed alcohol programs. ${ }^{99}$ Two systematic reviews, which included 90 unique observational studies and 1 qualitative meta-synthesis reported on supervised consumption facilities. ${ }^{124-126}$ For managed alcohol programs, 1 Cochrane review had no included studies, ${ }^{127}$ and 2 greyliterature reviews reported on 51 studies. ${ }^{128,129}$

Establishment of supervised consumption facilities was associated with a $35 \%$ decrease in the number of fatal opioid overdoses within 500 m of the facility (from 253.8 to 165.1 deaths per 100000 person years, $p=0.048$ ), compared with $9 \%$ in the rest of the city (Vancouver). ${ }^{124}$ There were 336 reported opioid overdose reversals in 90 different individuals within the Vancouver facility over a 4-year period (2004-2008). ${ }^{125}$ Similar protective effects were reported in Australia and Germany. Observational studies conducted in Vancouver and Sydney showed that regular use of supervised consumption facilities was associated with decreased syringe sharing (adjusted OR $0.30,95 \% \mathrm{Cl} 0.11$ to 0.82 ), syringe reuse (adjusted $\mathrm{OR} 2.04,95 \% \mathrm{Cl} 1.38$ to 3.01 ) and public-space injection (adjusted OR 2.79, $95 \% \mathrm{Cl} 1.93$ to 3.87 ). ${ }^{125}$ These facilities mediated access to ancillary services (e.g., food and shelter) and fostered access to broader health support. ${ }^{125,126}$ Attendance at supervised consumption facilities was associated with an increase in referrals to an addiction treatment centre and initiation of methadone maintenance therapy (adjusted hazard ratio $1.57,95 \% \mathrm{Cl} 1.02$ to 2.40$).{ }^{125}$
Evidence on supervised consumption facilities was rated very low to low, as all available evidence originated from nonrandomized studies.

There was a lack of high-quality evidence for managed alcohol programs. Few studies reported on deaths among clients of these programs. ${ }^{128}$ The effects of managed alcohol programs on hepatic function are mixed, with some studies reporting improvement in hepatic laboratory markers over time, and others showing increases in alcohol-related hepatic damage; ${ }^{129}$ however, this may have occurred regardless of entry into such a program. This evidence suggested that managed alcohol programs result in stabilized alcohol consumption and can facilitate engagement with medical and social services. ${ }^{128}$ Clients experienced significantly fewer social, health, safety and legal harms related to alcohol consumption. ${ }^{129}$ Individuals participating in these programs had fewer hospital admissions and a 93\% reduction in emergency service contacts. ${ }^{128}$ The programs also promoted improved or stabilized mental health ${ }^{128}$ and medication adherence. ${ }^{129}$

\section{Cost effectiveness and resource implications}

\section{Permanent supportive housing}

We found 19 studies assessing the cost and net cost of housing interventions. ${ }^{30,41,45,130-145}$ In some studies, permanent supportive housing interventions were associated with increased cost to the payers, and the costs of the interventions were only partially offset by savings in medical and social services as a result of the intervention. ${ }^{30,41,131-134,142}$ Six studies showed that these interventions saved payers money. ${ }^{135,137,139,141,144,145}$ Four of these studies, however, employed a pre-post design. ${ }^{135,139,141,145}$ Moreover, 1 cost-utility analysis of PSH suggested that the provision of housing services was associated with increased costs and increased quality-adjusted life years, with an incremental cost-effectiveness ratio of US\$62493 per quality-adjusted life year. ${ }^{136}$ Compared with usual care, PSH was found to be more costly to society (net cost Can\$7868, 95\% CI \$4409 to \$11405). ${ }^{138}$

\section{Income assistance}

Two studies ${ }^{55,146}$ focused on the cost effectiveness of incomeassistance interventions. Rental assistance with clients receiving case-management intervention had greater annual costs compared with usual care or groups receiving only case management. ${ }^{55}$ For each additional day housed, clients who received income assistance incurred additional costs of US\$58 $(95 \% \mathrm{CI} \$ 4$ to $\$ 111)$ from the perspective of the payer, US\$50 (95\% CI $-\$ 17$ to $\$ 117)$ from the perspective of the health care system and US\$45 $(95 \% \mathrm{Cl}-\$ 19$ to $\$ 108)$ from the societal perspective. The benefit gained from temporary financial assistance was found to outweigh its costs with a net savings of US\$20548. ${ }^{146}$

\section{Case management}

Twelve publications provided evidence on cost and costeffectiveness of case-management interventions. ${ }^{44,55,67,69,73,75,88,96,147-150}$ Findings of these studies were mixed; the total cost incurred by clients of standard case management was higher than that of clients receiving usual or standard care $^{61,88}$ and assertive 
community treatment, ${ }^{67,147}$ but lower compared with a US clinical case-management program that included housing vouchers and intensive case management. ${ }^{55}$ Cost-effectiveness studies using a societal perspective showed that standard case management was not cost effective compared with assertive community treatment for people with serious mental disorders or those with a concurrent substance-use disorder, as it was more expensive. ${ }^{67}$

For intensive case management, the cost of supporting housing with this program could be partially offset by reductions in the use of emergency shelters and temporary residences. ${ }^{41}$ Intensive case management is more likely to be cost effective when all costs and benefits to society are considered. ${ }^{41} \mathrm{~A}$ pre-post study showed that providing this program to high-need users of emergency departments resulted in a net hospital cost savings of US $\$ 132726 .{ }^{150}$

Assertive community treatment interventions were associated with lower costs compared with usual care. ${ }^{66,67,73,148,149}$ We identified only 1 study on the cost effectiveness of critical time intervention that reported comparable costs (US\$52574 v. US\$51749) of the treatment compared with the usual services provided to men with severe mental illness. ${ }^{96}$

\section{Interventions for substance use}

We identified 2 systematic reviews that reported findings from 6 studies in Vancouver on the cost effectiveness of supervised consumption facilities; ${ }^{124,125} 5$ of these 6 studies found the facilities to be cost effective. After consideration of facility operating costs, supervised consumption facilities saved up to Can\$6 million from averted overdose deaths and incident HIV cases. Similarly, Can\$1.8 million was saved annually from the prevention of incident $\mathrm{HCV}$ infection.

\section{Clinical considerations}

Providers can, in partnership with directly affected communities, employ a range of navigation and advocacy tools to address the root causes of homelessness, which include poverty caused by inadequate access to social assistance, precarious work, insufficient access to quality child care, social norms that allow the propagation of violence in homes and communities, inadequate supports for patients and families living with disabilities or going through life transitions, and insufficient and poor-quality housing stock. ${ }^{151}$ In addition, providers should tailor their approach to the patient's needs and demographics, taking into account access to services, personal preferences and other illnesses. ${ }^{152}$

Providers should also recognize the social and human value of accepting homeless and vulnerably housed people into their clinical practices. The following sections provide additional evidence for underserved and marginalized populations.

\section{Women}

A scoping review of the literature on interventions for homeless women (Christine Mathew, Bruyère Research Institute, Ottawa, Ont.: unpublished data, 2020) yielded 4 systematic reviews ${ }^{153-156}$ and 9 randomized controlled trials (RCTs) ) $^{36,60,92,95,157-161}$ that focused specifically on homeless and vulnerably housed women. Findings showed that PSH was effective in reducing the risk of intimate partner violence and improving psychological symptoms. ${ }^{158}$ For women with children experiencing homelessness, priority access to permanent housing subsidies can reduce child separations and foster care placements, allowing women to maintain the integrity of their family unit. ${ }^{158}$ As well, Housing First programs for families, critical time interventions during times of crisis, and therapeutic communities are associated with lower levels of psychological distress, increased self-esteem and improved quality of life for women and their families..$^{92,155} \mathrm{~A}$ gender-based analysis highlighted the importance of safety, service accessibility and empowerment among homeless women. We suggest that providers focus on patient safety, empowerment among women who have faced genderbased violence, and improve access to resources, including income, child care and other social support services.

\section{Youth}

A systematic review on youth-specific interventions reported findings from 4 systematic reviews and 18 RCTs. ${ }^{162}$ Permanent supportive housing improved housing stability. As well, individual cognitive behavioural therapy has been shown to result in significant improvements in depression scores, and family-based therapies are also promising, resulting in reductions in youth substance use through restoring the family dynamic. Findings on motivational interviewing, skill building and case-management interventions were inconsistent, with some trials showing a positive impact and others not identifying significant benefits.

\section{Refugee and migrant populations}

A qualitative systematic review on homeless migrants (Harneel Kaur, University of Ottawa, Ottawa, Ont.: unpublished data, 2020) identified 17 qualitative articles that focused on the experiences of homeless migrants. ${ }^{163-179}$ Findings indicated that discrimination, limited language proficiency and severed social networks negatively affected homeless migrants' sense of belonging and access to social services, such as housing. However, employment opportunities provided a sense of independence and improved social integration.

\section{Methods}

\section{Composition of participating groups}

In preparation for the guideline, we formed the Homeless Health Research Network (https://methods.cochrane.org/equity/ projects/homeless-health-guidelines), composed of clinicians, academics, and governmental and nongovernmental stakeholders. The Homeless Health Guideline Steering Committee (K.P. [chair], C.K., T.A., A.A., G.S., G.B., D.P., E.A., V.B., V.S. and P.T.) was assembled to coordinate guideline development. Expert representation was sought from eastern and western Canada, Ontario, Quebec and the Prairie provinces for membership on the steering committee. In addition, 5 people with lived experience of homelessness (herein referred to as "community scholars"180) were recruited to participate in the guideline-development activities. A management committee (K.P., C.K. and P.T.) oversaw the participating groups and monitored competing interests.

The steering committee decided to develop a single guideline publication informed by a series of 8 systematic reviews. The 
steering committee assembled expert working groups to operationalize each review. Each working group consisted of clinical topic experts and community scholars who were responsible for providing contextual expertise.

The steering committee also assembled a technical team, which provided technical expertise in the conduct and presentation of systematic reviews and meta-analyses. Finally, the steering committee assembled the guideline panel, which had the responsibility to provide external review of the evidence and drafted recommendations. The panel was composed of 17 individuals, including physicians, primary care providers, internists, psychiatrists, public health professionals, people with lived experience of homelessness, medical students and medical residents. Panel members had no financial or intellectual conflicts of interest. A full membership list of the individual teams' composition is available in Appendix 2, available at www.cmaj.ca/lookup/ suppl/doi:10.1503/cmaj.190777/-/DC1.

\section{Selection of priority topics}

We used a 3-step modified Delphi consensus method (Esther Shoemaker, Bruyère Research Institute, Ottawa, Ont.: unpublished data, 2020) to select priority health conditions for marginalized populations experiencing homelessness or vulnerable housing. Briefly, between May and June 2017, we developed and conducted a survey (in French and English), in which we asked 84 expert providers and 76 people with lived homelessness experience to rank and prioritize an initial list of needs and populations. We specifically asked participants, while answering the Delphi survey, to keep in mind 3 priority-setting criteria when considering the unique challenges of implementing health care for homeless or vulnerably housed people: value added (i.e., the opportunity for a unique and relevant contribution), reduction of unfair and preventable health inequities, and decrease in burden of illness (i.e., the number of people who may have a disease or condition). ${ }^{181}$

The initial top 4 priority needs identified were as follows: facilitating access to housing, providing mental health and addiction care, delivering care coordination and case management, and facilitating access to adequate income. The priority marginalized populations identified included Indigenous people; women and families; youth; people with acquired brain injury, or intellectual or physical disabilities; and refugees and other migrants (Esther Shoemaker, Bruyère Research Institute, Ottawa, Ont.: unpublished data, 2020). Each working group then scoped the literature using Google Scholar and PubMed to determine a list of interventions and terms relating to each of the priority-need categories. Each working group came to consensus on the final list of interventions to be included (Table 3 ).

\section{Guideline development}

We followed the GRADE (Grading of Recommendations Assessment, Development and Evaluation) approach for the development of this clinical guideline, including the identification of clinical questions, systematic reviews of the best available evidence,

Table 3: Descriptions of priority-need interventions

Intervention

Permanent supportive housing

Income assistance

Case management

Pharmacologic interventions for substance use disorder

Harm reduction for substance use disorders

\section{Description}

Long-term housing in the community with no set preconditions for access. Housing may be paired with the provision of individualized supportive services that are tailored to participants' needs and choices, including assertive community treatment and intensive case management.

- This guideline groups the Housing First model (a homeless assistance approach that prioritizes providing housing) with permanent supportive housing.

- Benefits and programs that improve socioeconomic status. This may include assistance that directly increases income and programs that help with cost reduction of basic living necessities.

- This guideline also groups employment programs (e.g., individual placement and support, and compensated work therapy) in this category.

- Standard case management allows for the provision of an array of social, health care and other services with the goal of helping the client maintain good health and social relationships.

- Intensive case management offers the support of a case manager who brokers access to an array of services. Case-management support can be available for up to 12 hours per day, 7 days a week, and each case manager often has a caseload of 15-20 service users.

- Assertive community treatment offers team-based care to individuals with severe and persistent mental illness by a multidisciplinary group of health care workers in the community. This team should be available 24 hours per day, 7 days per week.

- Critical time intervention supports continuity of care for service users during times of transition. Case management is administered by a critical time intervention worker and is a time-limited service, usually lasting 6-9 months.

Pharmacologic interventions for opioid use disorder, including methadone, buprenorphine, diacetylmorphine, levo- $\alpha$-acetylmethadol and naltrexone.

- Pharmacologic agents for reversal of opioid overdose: opioid antagonist administered intravenously or intranasally (e.g., naloxone).

- Supervised consumption facilities: facilities (stand-alone, co-located or pop-up) where people who use substances can consume preobtained substances under supervision.

- Managed alcohol programs: shelter, medical assistance, social services and the provision of regulated alcohol to support residents with severe alcohol use disorder. 
assessment of the certainty of the evidence and development of recommendations. ${ }^{182}$ We conducted a series of systematic reviews to answer the following clinical question:

Should PSH, income assistance, case management, pharmacologic agents for opioid use, and/or harm-reduction interventions be considered for people with lived experience of homelessness?

Systematic reviews for each intervention were driven by a logic model. A detailed description of the methods used to compile evidence summaries for each recommendation, including search terms, can be found in Appendix 3, available at www.cmaj.ca/ lookup/suppl/doi:10.1503/cmaj.190777/-/DC1. We sought evidence on questions considering population, interventions and comparisons according to published a priori protocols. ${ }^{183-186} \mathrm{We}$ used relevant terms and structured search strategies in 9 bibliographic databases for RCTs and quasi-experimental studies. The technical team reviewed titles, abstracts and full texts of identified citations, selected evidence for inclusion and compiled evidence reviews, including cost-effectiveness and resource-use data, for consideration by the guideline panel. The technical team collected and synthesized data on the following a priori outcomes: housing stability, mental health, quality of life, substance use, hospital admission, employment and income. Where possible, we conducted meta-analyses with random effects and assessed certainty of evidence using the GRADE approach. Where pooling of results was not appropriate, we synthesized results narratively.

In addition to the intervention and cost-effectiveness reviews, the technical team conducted 3 systematic reviews to collect contextual and population-specific evidence for the populations prioritized through our Delphi process (women, youth, refugees and migrants) (Christine Mathew, Bruyère Research Institute, Ottawa, Ont.: unpublished data, 2020; Harneel Kaur, University of Ottawa, Ottawa, Ont.: unpublished data, 2020). ${ }^{162}$ Additionally, we conducted 1 qualitative literature review to capture patient values and preferences, focused on the experiences of people who are homeless in engaging with our selected interventions. ${ }^{20}$

\section{Drafting of recommendations}

The steering committee hosted a 2-day knowledge-sharing event, termed the "Homeless Health Summit," on Nov. 25-26, 2018. Attendees included expert working group members, community scholars, technical team members, and other governmental and nongovernmental stakeholders. Findings from all intervention reviews were presented and discussed according to the GRADE Evidence to Decision framework. ${ }^{187}$ After the meeting, the steering committee drafted GRADE recommendations (Box 2) through an iterative consensus process. All steering-committee members participated in multiple rounds of review and revision of the drafted clinical recommendations.

\section{Guideline panel review}

We used the GRADE Evidence to Decision framework to facilitate the development of recommendations ${ }^{187-189}$ (Appendix 4, available at www.cmaj.ca/lookup/suppl/doi:10.1503/cmaj.190777/-/DC1). We used GRADEpro and the Panel Voice software to obtain input from the guideline panel. ${ }^{190}$ Panellists provided input on the wording and strength of the draft recommendations. They also provided considerations for clinical implementation. We required endorsement of recommendations by $60 \%$ of panel members for acceptance of a recommendation. After review by the guideline panel, the steering committee reviewed the final recommendations before sign-off.

\section{Good practice statements}

We developed a limited number of good practice statements to support the delivery of the initial evidence-based recommendations. A good practice statement characteristically represents situations in which a large and compelling body of indirect evidence strongly supports the net benefit of the recommended action, which is necessary for health care practice. ${ }^{191-193}$ Guideline-development groups consider making good practice statements when they have high confidence that indirect evidence supports net benefit, there is a clear and explicit rationale connecting the indirect evidence, and it would be an onerous and unproductive exercise and thus a poor use of the group's limited resources to collect this evidence. The steering committee came to a consensus on 3 good practice statements based on indirect evidence.

\section{Identification of implementation considerations}

We completed a mixed-methods study to identify determinants of implementation across Canada for the guideline (Olivia Magwood, Bruyère Research Institute, Ottawa, Ont.: unpublished data, 2020). Briefly, the study included a survey of 88 stakeholders and semistructured interviews with people with lived experience of homelessness. The GRADE Feasibility, Acceptability, Cost (affordability) and Equity (FACE) survey collected data on guideline priority, feasibility, acceptability, cost, equity and intent to implement. We used a framework analysis and a series of meetings (Ottawa, Ont., Jan. 13, 2020; Hamilton, Ont., Aug. 16, 2019; Gatineau, Que., July 18, 2019) with relevant stakeholders in the field of homeless health to analyze our implementation data.

\section{Management of competing interests}

Competing interests were assessed using a detailed form adapted from the International Committee of Medical Journal Editors Uniform Disclosure Form for Potential Conflicts of Interest ${ }^{194}$ and the Elsevier sample coauthor agreement form for a scientific project, contingencies and communication. ${ }^{195}$ These forms were collected at the start of the guideline activities for the steering committee, guideline panel and community scholars. All authors submitted an updated form in June 2019 and before publication.

The management committee iteratively reviewed these statements and interviewed participants for any clarifications and concerns. A priori, the management committee had agreed that major competing interests would lead to dismissal. There were no competing interests declared.

\section{Implementation}

Our mixed-methods study (Olivia Magwood, Bruyère Research Institute, Ottawa, Ont.: unpublished data, 2020) looking at guideline priority, feasibility, acceptability, cost, equity and intent to implement, identified the following concerns regarding implementation of this guideline. 
Stakeholders highlighted the importance of increasing primary care providers' knowledge of the process of applying to PSH programs and informing their patients about the resources available in the community.

The major concerns regarding feasibility arose around the limited availability of existing services, such as housing, as well as administrative and human resources concerns. For example, not all primary care providers work in a team-based comprehensive care model and have access to a social worker or care coordinator who can help link the patient to existing services. Furthermore, wait lists for PSH are frequently long. Despite this, all stakeholders agreed that access to PSH was a priority and is a feasible recommendation.

Allied health practitioners and physicians do not always agree with their new role in this area. Some feedback suggested pushback from family physicians who have limited time with patients and less experience exploring social determinants of health, such as housing or income. The initial steps outlined in this guideline would come at an opportunity cost for them. Stigma attached to the condition of homelessness was recognized as an important barrier to care for homeless populations.

Many stakeholders recognized that successful implementation of these recommendations may require moderate costs to increase the housing supply, income supports and human resources. However, supervised consumption facilities, with their range of benefits, were perceived as cost-saving.

Many interventions have the potential to increase health equity, if available and accessible in a local context. Many stakeholders highlighted opportunities to increase knowledge of the initial steps and advocate on a systematic level to increase availability of services.

\section{Suggested performance measures}

We developed a set of performance measures to accompany this guidleline for consideration by providers and policy-makers:

- The proportion of adults who are assessed for homelessness or vulnerable housing over 1 year.

- The proportion of eligible adults who are considered for income assistance over 1 year.

- The proportion of eligible adults using opioids who are offered opioid agonist therapy over 1 year.

\section{Updates}

The Homeless Health Research Network will be responsible for updating this guideline every 5 years.

\section{Other guidelines}

This guideline complements other published guidelines. This current guideline aims to support the upcoming Indigenousspecific guidelines that recognize the importance of Indigenous leadership and methodology that will recognize distinct underlying causes of Indigenous homelessness (Jesse Thistle, York University, Toronto, Ont.: personal communication, 2020).

The World Health Organization has developed guidelines to promote healthy housing standards to save lives, prevent disease and increase quality of life. ${ }^{196}$ Other guidelines specific to opioid use disorder exist, ${ }^{197,198}$ including 1 for "treatment-refractory" patients. ${ }^{199}$ In the United Kingdom, the National Institute for Health Care and Excellence has published guidelines for outpatient treatment of schizophrenia and has published multimorbidity guidelines (www.nice.org.uk/guidance). The National Health Care for the Homeless Council in the US has adapted best practices to support front-line workers caring for homeless populations. ${ }^{200}$

\section{How is this guideline different?}

This guideline distills initial steps and evidence-based approaches, to both homeless and vulnerably housed people, with the assistance of patients and other stakeholders. It also introduces a new clinical lens with upstream interventions that provide a social and health foundation for community integration. Its initial steps support the vision of the Centre for Homelessness Impact in the UK, which envisions a society where the experience of homelessness, in instances where it cannot be prevented, is only ever rare, brief and nonrecurrent. ${ }^{201}$ Finally, we hope that our stakeholder engagement inspires and equips future students, health providers and the public health community to implement the initial step recommendations.

\section{Gaps in knowledge}

Evidence-based policy initiatives will need to address the accelerating health and economic disparities between homeless and general housed populations. As primary care expands its medical home models, ${ }^{27}$ there will be a research opportunity for more traumainformed care ${ }^{202}$ to support the evidence-based interventions in this guideline. Indeed, clinical research can refine how providers use the initial steps protocol: housing, income, case management and addiction. With improved living conditions, care coordination and continuity of care, research and practice can shift to treatable conditions, such as HIV and HCV infection, substance use disorder, mental illness and tuberculosis. ${ }^{203}$

Medical educators will also need to develop new training tools to support the delivery of interventions. Curricula and training that support the delivery of interventions, such as traumainformed and patient-centred care, will also be needed. ${ }^{12}$ Many of the recommended interventions in this guideline rely on collaboration of community providers, housing coordinators and case management. Interdisciplinary primary care research and maintenance of linkages to primary care will benefit from new homeless health clinic networks. Monitoring transitions in care and housing availability will be an important research goal for Canada's National Housing Strategy and the associated Reaching Home program.

\section{Conclusion}

Homelessness has become a health emergency. Initial steps in addressing this crisis proposed in this guideline include strongly recommending PSH as an urgent intervention. The guideline also recognizes the trauma, disability, mental illness and stigma 
facing people with lived homelessness experience and thus recommends initial steps of income assistance, intensive case management for mental illness, and harm-reduction and addictiontreatment interventions, including access to opioid agonist therapy and supervised consumption facilities.

The successful implementation of this guideline will depend on a focus on the initial recommendations, trust, patient safety and an ongoing collaboration between primary health care, mental health providers, public health, people with lived experience and broader community organizations, including those beyond the health care field.

\section{References}

1. Frankish CJ, Hwang SW, Quantz D. Homelessness and health in Canada: research lessons and priorities. Can J Public Health 2005;96(Suppl 2):S23-9.

2. 31 days of promoting a better urban future: Report 2018. Nairobi (Kenya): UN Habitat, United Nations Human Settlement Programme; 2018. Available: https://oldweb.unhabitat.org/wp-content/uploads/2019/01/Final-short-version -UN-Habitat-Urban-October-Report.pdf (accessed 2019 Apr. 1).

3. Wen CK, Hudak PL, Hwang SW. Homeless people's perceptions of welcomeness and unwelcomeness in healthcare encounters. J Gen Intern Med 2007;22:1011-7.

4. Coltman L, Gapka S, Harriott D, et al. Understanding community integration in a housing-first approach: Toronto At Home/Chez Soi community-based research. Intersectionalities 2015;4:39-50.

5. Hwang SW, Burns T. Health interventions for people who are homeless. Lancet 2014;384:1541-7.

6. Canadian definition of homelessness. Toronto: Canadian Observatory on Homelessness; 2012. Available: www.homelesshub.ca/sites/default/files/ attachments/Definition of Homelessness.pdf (accessed 2019 Apr. 1).

7. Hwang SW, Wilkins R, Tjepkema M, et al. Mortality among residents of shelters, rooming houses, and hotels in Canada: 11 year follow-up study. BMJ 2009;339: b4036.

8. Nordentoft M, Wandall-Holm N. 10 year follow up study of mortality among users of hostels for homeless people in Copenhagen. BMJ 2003;327:81.

9. Fazel S, Geddes JR, Kushel M. The health of homeless people in high-income countries: descriptive epidemiology, health consequences, and clinical and policy recommendations. Lancet 2014;384:1529-40.

10. Gaetz S, Dej E, Richter T, et al. The state of homelessness in Canada 2016. Toronto: Canadian Observatory on Homelessness Press; 2016.

11. Thistle J. Indigenous definition of homelessness in Canada. Toronto: Canadian Observatory on Homelessness Press; 2017.

12. Belanger YD, Awosoga O, Head GW. Homelessness, urban Aboriginal people, and the need for a national enumeration. Aboriginal Policy Studies 2013;2: 4-33.

13. Taylor M. How is rural homelessness different from urban homelessness? Toronto: The Canadian Observatory on Homelessness/Homeless Hub; 2018. Available: www.homelesshub.ca/blog/how-rural-homelessness-different -urban-homelessness (accessed 2019 Feb. 6).

14. Rodrigue S. Hidden homelessness in Canada. Cat no 75-006-X. Ottawa: Statistics Canada; 2016.

15. Gulliver-Garcia T. Putting an end to child \& family homelessness in Canada. Toronto: Raising the Roof; 2016.

16. Andermann A.; CLEAR Collaboration. Taking action on the social determinants of health in clinical practice: a framework for health professionals. CMAJ 2016; 188:E474-83.

17. Jackson GL, Powers BJ, Chatterjee R, et al. The patient-centered medical home: a systematic review. Ann Intern Med 2013;158:169-78.

18. A new vision for Canada: family practice - the patient's medical home 2019. Mississauga (ON): The College of Family Physicians of Canada; 2019.

19. Declaration of Alma-Ata. Proceedings of the International Conference on Primary Health Care, Alma-Ata; 1978 Sept. 6-12. Geneva: World Health Organization.

20. Magwood O, Leki VY, Kpade V, et al. Common trust and personal safety issues: A systematic review on the acceptability of health and social interventions for persons with lived experience of homelessness. PLoS One 2019;14:e0226306.

21. Luchenski S, Maguire N, Aldridge RW, et al. What works in inclusion health: overview of effective interventions for marginalised and excluded populations. Lancet 2018;391:266-80.
22. Thistle JA, Laliberte N. Pekiwewin (Coming Home): Clinical practice guidelines for health and social service providers working with Indigenous people experiencing homelessness. Verbal concurrent session presented at the Canadian Alliance to End Homelessness Conference, 2019 Nov. 4; Edmonton.

23. Stewart MA. Effective physician-patient communication and health outcomes: a review. CMAJ 1995;152:1423-33.

24. Racine N, Killam T, Madigan S. Trauma-informed care as a universal precaution: beyond the adverse childhood experiences questionnaire. JAMA Pediatr 2019 Nov. 4 [Epub ahead of print]. doi: 10.1001/jamapediatrics.2019.3866.

25. Reeves E. A synthesis of the literature on trauma-informed care. Issues Ment Health Nurs 2015;36:698-709.

26. Hopper E, Bassuk E, Olivet J. Shelter from the storm: trauma-informed care in homelessness services settings. Open Health Serv Policy J 2009;2:131-51.

27. A new vision for Canada: family practice - The patient's medical home. Mississauga (ON): College of Family Physicians of Canada; 2019. Available: www. cfpc.ca/A_Vision_for_Canada (accessed 2019 Dec. 2).

28. Valaitis RK, O'Mara L, Wong ST, et al. Strengthening primary health care through primary care and public health collaboration: the influence of intrapersonal and interpersonal factors. Prim Health Care Res Dev 2018;19:378-91.

29. Akhtar-Danesh N, Valaitis R, O'Mara L, et al. Viewpoints about collaboration between primary care and public health in Canada. BMC Health Serv Res 2013;13:311.

30. Aubry T, Goering P, Veldhuizen S, et al. A multiple-city RCT of housing first with assertive community treatment for homeless Canadians with serious mental illness. Psychiatr Serv 2016;67:275-81.

31. Cherner RA, Aubry T, Sylvestre J, et al. Housing first for adults with problematic substance use. J Dual Diagn 2017;13:219-29.

32. Goldfinger SM, Schutt RK, Tolomiczenko GS, et al. Housing placement and subsequent days homeless among formerly homeless adults with mental illness. Psychiatr Serv 1999;50:674-9.

33. Hwang SW, Gogosis E, Chambers C, et al. Health status, quality of life, residential stability, substance use, and health care utilization among adults applying to a supportive housing program. J Urban Health 2011;88:1076-90.

34. Lipton FR, Nutt S, Sabatini A. Housing the homeless mentally ill: a longitudinal study of a treatment approach. Hosp Community Psychiatry 1988;39:40-5.

35. Martinez TE, Burt MR. Impact of permanent supportive housing on the use of acute care health services by homeless adults. Psychiatr Serv 2006;57:992-9.

36. McHugo GJ, Bebout RR, Harris M, et al. A randomized controlled trial of integrated versus parallel housing services for homeless adults with severe mental illness. Schizophr Bull 2004;30:969-82.

37. Rich AR, Clark C. Gender differences in response to homelessness services. Eval Program Plann 2005;28:69-81. doi: 10.1016/j.evalprogplan.2004.05.003.

38. Sadowski LS, Kee RA, VanderWeele TJ, et al. Effect of a housing and case management program on emergency department visits and hospitalizations among chronically ill homeless adults: a randomized trial. JAMA 2009;301:1771-8.

39. Siegel CE, Samuels J, Tang D-I, et al. Tenant outcomes in supported housing and community residences in New York City. Psychiatr Serv 2006;57:982-91.

40. Stefancic A, Tsemberis S. Housing First for long-term shelter dwellers with psychiatric disabilities in a suburban county: a four-year study of housing access and retention. J Prim Prev 2007;28:265-79.

41. Stergiopoulos V, Hwang SW, Gozdzik A, et al.; At Home/Chez Soi Investigators. Effect of scattered-site housing using rent supplements and intensive case management on housing stability among homeless adults with mental illness: a randomized trial. JAMA 2015;313:905-15.

42. Tsemberis S, Gulcur L, Nakae M. Housing First, consumer choice, and harm reduction for homeless individuals with a dual diagnosis. Am J Public Health 2004;94:651-6.

43. Young MS, Clark C, Moore K, et al. Comparing two service delivery models for homeless individuals with complex behavioral health needs: preliminary data from two SAMHSA treatment for homeless studies. J Dual Diagn 2009;5: 287-304.

44. Kozloff N, Adair CE, Palma Lazgare LI, et al. "Housing First" for homeless youth with mental illness. Pediatrics 2016;138:e20161514.

45. Gulcur L, Stefancic A, Shinn M, et al. Housing, hospitalization, and cost outcomes for homeless individuals with psychiatric disabilities participating in continuum of care and housing first programmes. J Community Appl Soc Psychol 2003;13:171-86. doi: 10.1002/casp.723.

46. Poremski D, Stergiopoulos V, Braithwaite E, et al. Effects of Housing First on employment and income of homeless individuals: results of a randomized trial. Psychiatr Serv 2016;67:603-9.

47. Booshehri LG, Dugan J, Patel F, et al. Trauma-informed Temporary Assistance for Needy Families (TANF): a randomized controlled trial with a twogeneration impact. J Child Fam Stud 2018;27:1594-604. 
48. Ferguson KM. Employment outcomes from a randomized controlled trial of two employment interventions with homeless youth. J Soc Social Work Res 2018;9:1-21.

49. Forchuk C, MacClure SK, Van Beers M, et al. Developing and testing an intervention to prevent homelessness among individuals discharged from psychiatric wards to shelters and "No Fixed Address". J Psychiatr Ment Health Nurs 2008;15:569-75.

50. Gubits D, Shinn M, Wood M, et al. What interventions work best for families who experience homelessness? Impact estimates from the family options study. J Policy Anal Manage 2018;37:735-66.

51. Hurlburt MS, Hough RL, Wood PA. Effects of substance abuse on housing stability of homeless mentally III persons in supported housing. Psychiatr Serv 1996;47:731-6.

52. Kashner TM, Rosenheck R, Campinell AB, et al. Impact of work therapy on health status among homeless, substance-dependent veterans: a randomized controlled trial. Arch Gen Psychiatry 2002;59:938-44.

53. Pankratz C, Nelson G, Morrison M. A quasi-experimental evaluation of rent assistance for individuals experiencing chronic homelessness. J Community Psychol 2017;45:1065-79. doi: 10.1002/jcop.21911.

54. Poremski D, Distasio J, Hwang SW, et al. Employment and income of people who experience mental illness and homelessness in a large Canadian sample. Can J Psychiatry 2015;60:379-85.

55. Rosenheck R, Kasprow W, Frisman L, et al. Cost-effectiveness of supported housing for homeless persons with mental illness. Arch Gen Psychiatry 2003; 60:940-51.

56. Wolitski RJ, Kidder DP, Pals SL, et al.; Housing and Health Study Team. Randomized trial of the effects of housing assistance on the health and risk behaviors of homeless and unstably housed people living with HIV. AIDS Behav 2010;14:493-503.

57. Conrad KJ, Hultman $\mathrm{Cl}$, Pope AR, et al. Case managed residential care for homeless addicted veterans. Results of a true experiment. Med Care 1998; 36:40-53.

58. Graham-Jones S, Reilly S, Gaulton E. Tackling the needs of the homeless: a controlled trial of health advocacy. Health Soc Care Community 2004;12:221-32.

59. Lapham SC, Hall M, Skipper BJ. Homelessness and substance use among alcohol abusers following participation in project H\&ART. J Addict Dis 1995;14:41-55.

60. Nyamathi A, Flaskerud JH, Leake B, et al. Evaluating the impact of peer, nurse case-managed, and standard HIV risk-reduction programs on psychosocial and health-promoting behavioral outcomes among homeless women. Res Nurs Health 2001;24:410-22.

61. Nyamathi AM, Zhang S, Salem BE, et al. A randomized clinical trial of tailored interventions for health promotion and recidivism reduction among homeless parolees: outcomes and cost analysis. J Exp Criminol 2016;12:49-74.

62. Sosin MR, Bruni M, Reidy M. Paths and impacts in the progressive independence model: a homelessness and substance abuse intervention in Chicago. J Addict Dis 1995;14:1-20.

63. Towe VL, Wiewel EW, Zhong Y, et al. A randomized controlled trial of a rapid rehousing intervention for homeless persons living with HIV/AIDS: impact on housing and HIV medical outcomes. AIDS Behav 2019;23:2315-25.

64. Upshur C, Weinreb L, Bharel M, et al. A randomized control trial of a chronic care intervention for homeless women with alcohol use problems. J Subst Abuse Treat 2015;51:19-29.

65. Weinreb L, Upshur CC, Fletcher-Blake D, et al. Managing depression among homeless mothers: pilot testing an adapted collaborative care intervention. Prim Care Companion CNS Disord 2016;18.

66. Clarke GN, Herinckx HA, Kinney RF, et al. Psychiatric hospitalizations, arrests, emergency room visits, and homelessness of clients with serious and persistent mental illness: findings from a randomized trial of two ACT programs vs. usual care. Ment Health Serv Res 2000;2:155-64.

67. Essock SM, Frisman LK, Kontos NJ. Cost-effectiveness of assertive community treatment teams. Am J Orthopsychiatry 1998;68:179-90.

68. Essock SM, Mueser KT, Drake RE, et al. Comparison of ACT and standard case management for delivering integrated treatment for co-occurring disorders. Psychiatr Serv 2006;57:185-96.

69. Fletcher TD, Cunningham JL, Calsyn RJ, et al. Evaluation of treatment programs for dual disorder individuals: modeling longitudinal and mediation effects. Adm Policy Ment Health 2008;35:319-36.

70. Lehman AF, Dixon LB, Kernan E, et al. A randomized trial of assertive community treatment for homeless persons with severe mental illness. Arch Gen Psychiatry 1997; 54:1038-43.

71. Morse GA, Calsyn RJ, Allen G, et al. Experimental comparison of the effects of three treatment programs for homeless mentally ill people. Hosp Community Psychiatry 1992;43:1005-10.
72. Morse GA, Calsyn RJ, Klinkenberg WD, et al. An experimental comparison of three types of case management for homeless mentally ill persons. Psychiatr Serv 1997;48:497-503.

73. Morse GA, Calsyn RJ, Klinkenberg WD, et al. Treating homeless clients with severe mental illness and substance use disorders: costs and outcomes. Community Ment Health J 2006;42:377-404.

74. Braucht GN, Reichardt CS, Geissler LJ, et al. Effective services for homeless substance abusers. J Addict Dis 1995;14:87-109.

75. Burnam MA, Morton SC, McGlynn EA, et al. An experimental evaluation of residential and nonresidential treatment for dually diagnosed homeless adults. J Addict Dis 1995;14:111-34.

76. Cauce AM, Morgan CJ, Wagner V, et al. Effectiveness of intensive case management for homeless adolescents: rof a 3-month follow-up. J Emot Behav Disord 1994;2:219-27.

77. Clark C, Rich AR. Outcomes of homeless adults with mental illness in a housing program and in case management only. Psychiatr Serv 2003;54:78-83.

78. Cox GB, Walker RD, Freng SA, et al. Outcome of a controlled trial of the effectiveness of intensive case management for chronic public inebriates. J Stud Alcohol 1998;59:523-32.

79. Felton CJ, Stastny P, Shern DL, et al. Consumers as peer specialists on intensive case management teams: impact on client outcomes. Psychiatr Serv 1995; 46:1037-44.

80. Grace M, Gill PR. Improving outcomes for unemployed and homeless young people: findings of the YP4 clinical controlled trial of joined up case management. Aust Soc Work 2014;67:419-37.

81. Korr WS, Joseph A. Housing the homeless mentally ill: Findings from Chicago. J Soc Serv Res 1996;21:53-68.

82. Malte CA, Cox K, Saxon AJ. Providing intensive addiction/housing case management to homeless veterans enrolled in addictions treatment: a randomized controlled trial. Psychol Addict Behav 2017;31:231-41.

83. Marshall M, Lockwood A, Gath D. Social services case-management for longterm mental disorders: a randomised controlled trial. Lancet 1995;345:409-12.

84. Orwin RG, Sonnefeld LJ, Garrison-Mogren R, et al. Pitfalls in evaluating the effectiveness of case management programs for homeless persons: lessons from the NIAAA Community Demonstration Program. Eval Rev 1994;18: 153-207.

85. Rosenblum A, Nuttbrock L, McQuistion H, et al. Medical outreach to homeless substance users in New York City: preliminary results. Subst Use Misuse 2002; 37:1269-73.

86. Shern DL, Tsemberis S, Anthony W, et al. Serving street-dwelling individuals with psychiatric disabilities: outcomes of a psychiatric rehabilitation clinical trial. Am J Public Health 2000;90:1873-8.

87. Stahler GJ, Shipley TF Jr, Bartelt D, et al. Evaluating alternative treatments for homeless substance-abusing men: outcomes and predictors of success. J Addict Dis 1996;14:151-67.

88. Shumway M, Boccellari A, O'Brien K, et al. Cost-effectiveness of clinical case management for ED frequent users: results of a randomized trial. Am J Emerg Med 2008;26:155-64.

89. Toro PA, Passero Rabideau JM, Bellavia CW, et al. Evaluating an intervention for homeless persons: results of a field experiment. J Consult Clin Psychol 1997;65:476-84.

90. de Vet R, Beijersbergen MD, Jonker IE, et al. Critical time intervention for homeless people making the transition to community living: a randomized controlled trial. Am J Community Psychol 2017;60:175-86.

91. Herman DB, Conover S, Gorroochurn P, et al. Randomized trial of critical time intervention to prevent homelessness after hospital discharge. Psychiatr Serv 2011;62:713-9.

92. Lako DAM, Beijersbergen MD, Jonker IE, et al. The effectiveness of critical time intervention for abused women leaving women's shelters: a randomized controlled trial. Int J Public Health 2018;63:513-23.

93. Shinn M, Samuels J, Fischer SN, et al. Longitudinal impact of a family critical time intervention on children in high-risk families experiencing homelessness: a randomized trial. Am J Community Psychol 2015;56:205-16.

94. Susser E, Valencia E, Conover S, et al. Preventing recurrent homelessness among mentally ill men: a" critical time" intervention after discharge from a shelter. Am J Public Health 1997;87:256-62.

95. Samuels J, Fowler PJ, Ault-Brutus A, et al. Time-limited case management for homeless mothers with mental health problems: effects on maternal mental health. J Soc Social Work Res 2015;6:515-39.

96. Jones K, Colson PW, Holter MC, et al. Cost-effectiveness of critical time intervention to reduce homelessness among persons with mental illness. Psychiatr Serv 2003;54:884-90. 
97. Tomita A, Herman DB. The impact of critical time intervention in reducing psychiatric rehospitalization after hospital discharge. Psychiatr Serv 2012;63: 935-7.

98. Jones $\mathrm{K}$, Colson $\mathrm{P}$, Valencia $\mathrm{E}$, et al. A preliminary cost effectiveness analysis of an intervention to reduce homelessness among the mentally ill. Psychiatr $Q$ 1994;65:243-56.

99. Magwood O, Salvalaggio G, Beder M, et al. The effectiveness of substance use interventions for homeless and vulnerably housed persons: a systematic review of systematic reviews on supervised consumption facilities, managed alcohol programs, and pharmacological agents for opioid use disorder. PLoS ONE 15(1):e0227298. https://doi.org/10.1371/journal.pone.0227298.

100. Bahji A, Bajaj N. Opioids on trial: a systematic review of interventions for the treatment and prevention of opioid overdose. Can J Addict 2018;9:26-33.

101. Clark N, Lintzeris N, Gijsbers A, et al. LAAM maintenance vs methadone maintenance for heroin dependence. Cochrane Database Syst Rev 2002;(2):CD002210.

102. Ferri M, Davoli M, Perucci CA. Heroin maintenance treatment for chronic heroin-dependent individuals: a Cochrane systematic review of effectiveness. J Subst Abuse Treat 2006;30:63-72.

103. Gowing L, Farrell MF, Bornemann R, et al. Oral substitution treatment of injecting opioid users for prevention of HIV infection. Cochrane Database Syst Rev 2011;(8):CD004145.

104. Jones HE, Heil SH, Baewert A, et al. Buprenorphine treatment of opioiddependent pregnant women: a comprehensive review. Addiction 2012; 107(Suppl 1):5-27.

105. Karki P, Shrestha R, Huedo-Medina TB, et al. The impact of methadone maintenance treatment on HIV risk behaviors among high-risk injection drug users: a systematic review. Evid Based Med Public Health 2016;2:pii: e1229.

106. Kirchmayer U, Davoli M, Verster AD, et al. A systematic review on the efficacy of naltrexone maintenance treatment in opioid dependence. Addiction 2002;97: 1241-9.

107. Larney S, Gowing L, Mattick RP, et al. A systematic review and meta-analysis of naltrexone implants for the treatment of opioid dependence. Drug Alcohol Rev 2014;33:115-28.

108. Lobmaier P, Kornør H, Kunøe N, et al. Sustained-release naltrexone for opioid dependence. Cochrane Database Syst Rev 2008;(2):CD006140.

109. Mattick RP, Breen C, Kimber J, et al. Buprenorphine maintenance versus placebo or methadone maintenance for opioid dependence. Cochrane Database Syst Rev 2014;(2):CD002207.

110. Mattick RP, Breen C, Kimber J, et al. Methadone maintenance therapy versus no opioid replacement therapy for opioid dependence. Cochrane Database Syst Rev 2009;(3):CD002209.

111. Minozzi S, Amato L, Vecchi S, et al. Oral naltrexone maintenance treatment for opioid dependence. Cochrane Database Syst Rev 2011;(4):CD001333.

112. Platt L, Minozzi S, Reed J, et al. Needle syringe programmes and opioid substitution therapy for preventing hepatitis $C$ transmission in people who inject drugs. Cochrane Database Syst Rev 2017;9:CD012021.

113. Roozen HG, de Waart R, van der Windt DAWM, et al. A systematic review of the effectiveness of naltrexone in the maintenance treatment of opioid and alcohol dependence. Eur Neuropsychopharmacol 2006;16:311-23.

114. Saulle R, Vecchi S, Gowing L. Supervised dosing with a long-acting opioid medication in the management of opioid dependence. Cochrane Database Syst Rev 2017;4:CD011983.

115. Simoens S, Matheson C, Bond C, et al. The effectiveness of community maintenance with methadone or buprenorphine for treating opiate dependence. $\mathrm{Br} J$ Gen Pract 2005;55:139-46.

116. Sordo L, Barrio G, Bravo MJ, et al. Mortality risk during and after opioid substitution treatment: systematic review and meta-analysis of cohort studies. BMJ 2017;357:j1550.

117. Helm S, Trescot AM, Colson J, et al. Opioid antagonists, partial agonists, and agonists/antagonists: the role of office-based detoxification. Pain Physician 2008;11:225-35.

118. Strang J, Groshkova T, Uchtenhagen A, et al. Heroin on trial: systematic review and meta-analysis of randomised trials of diamorphine-prescribing as treatment for refractory heroin addiction. Br J Psychiatry 2015;207:5-14.

119. Thomas CP, Fullerton CA, Kim M, et al. Medication-assisted treatment with buprenorphine: assessing the evidence. Psychiatr Serv 2014;65:158-70.

120. Weinmann S, Kunstmann W, Rheinberger P. Methadone substitution - a scientific review in the context of out-patient therapy in Germany [article in German]. Z Arztl Fortbild Qualitatssich 2004;98:673-82.

121. Wilder C, Lewis D, Winhusen T. Medication assisted treatment discontinuation in pregnant and postpartum women with opioid use disorder. Drug Alcohol Depend 2015;149:225-31.
122. Klimas J, Gorfinkel L, Giacomuzzi SM, et al. Slow release oral morphine versus methadone for the treatment of opioid use disorder. BMJ Open 2019;9: e025799.

123. Maglione MA, Raaen L, Chen C, et al. Effects of medication assisted treatment (MAT) for opioid use disorder on functional outcomes: a systematic review. J Subst Abuse Treat 2018;89:28-51.

124. Kennedy MC, Karamouzian M, Kerr T. Public health and public order outcomes associated with supervised drug consumption facilities: a systematic review. Curr HIV/AIDS Rep 2017;14:161-83.

125. Potier C, Laprévote V, Dubois-Arber F, et al. Supervised injection services: what has been demonstrated? A systematic literature review. Drug Alcohol Depend 2014;145:48-68.

126. McNeil R, Small W. 'Safer environment interventions': a qualitative synthesis of the experiences and perceptions of people who inject drugs. Soc Sci Med 2014;106:151-8.

127. Muckle W, Muckle J, Welch V, et al. Managed alcohol as a harm reduction intervention for alcohol addiction in populations at high risk for substance abuse. Cochrane Database Syst Rev 2012;12:CD006747.

128. Ezard N, Dolan K, Baldry E, et al. Feasibility of a Managed Alcohol Program (MAP) for Sydney's homeless. Canberra (AU): Foundation for Alcohol Research and Education; 2015.

129. Nielsen E, Novotna G, Berenyi R, et al. Harm reduction interventions for chronic and severe alcohol use among populations experiencing homelessness: a literature review. Regina: University of Regina, Carmichael Outreach Inc.; 2018.

130. Basu A, Kee R, Buchanan D, et al. Comparative cost analysis of housing and case management program for chronically ill homeless adults compared to usual care. Health Serv Res 2012;47:523-43.

131. Culhane DP, Metraux S, Hadley T. Public service reductions associated with placement of homeless persons with severe mental illness in supportive housing. Hous Policy Debate 2002;13:107-63.

132. Dickey B, Latimer E, Powers K, et al. Housing costs for adults who are mentally ill and formerly homeless. J Ment Health Adm 1997;24:291-305.

133. Gilmer TP, Manning WG, Ettner SL. A cost analysis of San Diego County's REACH program for homeless persons. Psychiatr Serv 2009;60:445-50.

134. Gilmer TP, Stefancic A, Ettner SL, et al. Effect of full-service partnerships on homelessness, use and costs of mental health services, and quality of life among adults with serious mental illness. Arch Gen Psychiatry 2010;67:645-52.

135. Hunter S, Harvey M, Briscombe B, et al. Evaluation of housing for health permanent supportive housing program. Santa Monica (CA): RAND Corporation; 2017.

136. Holtgrave DR, Wolitski RJ, Pals SL, et al. Cost-utility analysis of the housing and health intervention for homeless and unstably housed persons living with HIV. AIDS Behav 2013;17:1626-31.

137. Larimer ME, Malone DK, Garner MD, et al. Health care and public service use and costs before and after provision of housing for chronically homeless persons with severe alcohol problems. JAMA 2009;301:1349-57.

138. Latimer EA, Rabouin D, Cao Z, et al.; At Home/Chez Soi Investigators. Costeffectiveness of Housing First intervention with intensive case management compared with treatment as usual for homeless adults with mental illness: secondary analysis of a randomized clinical trial. JAMA Netw Open 2019; 2:e199782.

139. Lenz-Rashid S. Supportive housing program for homeless families: Foster care outcomes and best practices. Child Youth Serv Rev 2017;79:558-63.

140. Lim S, Gao Q, Stazesky E, et al. Impact of a New York City supportive housing program on Medicaid expenditure patterns among people with serious mental illness and chronic homelessness. BMC Health Serv Res 2018;18:15.

141. McLaughlin TC. Using common themes: cost-effectiveness of permanent supported housing for people with mental illness. Res Soc Work Pract 2010;21: 404-11.

142. Mares AS, Rosenheck RA. A comparison of treatment outcomes among chronically homelessness adults receiving comprehensive housing and health care services versus usual local care. Adm Policy Ment Health 2011;38:459-75.

143. Pauley T, Gargaro J, Falode A, et al. Evaluation of an integrated cluster care and supportive housing model for unstably housed persons using the shelter system. Prof Case Manag 2016;21:34-42.

144. Schinka JA, Francis E, Hughes $P$, et al. Comparative outcomes and costs of inpatient care and supportive housing for substance-dependent veterans. Psychiatr Serv 1998;49:946-50.

145. Srebnik D, Connor T, Sylla L. A pilot study of the impact of housing firstsupported housing for intensive users of medical hospitalization and sobering services. Am J Public Health 2013;103:316-21.

146. Evans WN, Sullivan JX, Wallskog M. The impact of homelessness prevention programs on homelessness. Science 2016;353:694-9. 
147. Clark RE, Teague GB, Ricketts SK, et al. Cost-effectiveness of assertive community treatment versus standard case management for persons with cooccurring severe mental illness and substance use disorders. Health Serv Res 1998;33:1285-308.

148. Lehman AF, Dixon L, Hoch JS, et al. Cost-effectiveness of assertive community treatment for homeless persons with severe mental illness. $\mathrm{Br} J$ Psychiatry 1999;174:346-52.

149. Wolff N, Helminiak TW, Morse GA, et al. Cost-effectiveness evaluation of three approaches to case management for homeless mentally ill clients. Am J Psychiatry 1997;154:341-8.

150. Okin RL, Boccellari A, Azocar F, et al. The effects of clinical case management on hospital service use among ED frequent users. Am J Emerg Med 2000;18:603-8.

151. Hwang SW. Homelessness in health. CMAJ 2001;164:229-33.

152. National Clinical Guideline Centre (UK). Patient experience in adult NHS services: improving the experience of care for people using adult NHS services patient experience in generic terms. NICE Clinical Guidelines No 138. London (UK): Royal College of Physicians; 2012. Available: www.ncbi.nlm.nih.gov/ books/NBK115230 (accessed 2019 Dec. 12).

153. Jonker IE, Sijbrandij M, Van Luijtelaar MJA, et al. The effectiveness of interventions during and after residence in women's shelters: a meta-analysis. Eur J Public Health 2015;25:15-9.

154. Rivas C, Ramsay J, Sadowski L, et al. Advocacy interventions to reduce or eliminate violence and promote the physical and psychosocial well-being of women who experience intimate partner abuse. Cochrane Database Syst Rev 2015;(12):CD005043.

155. Speirs V, Johnson M, Jirojwong S. A systematic review of interventions for homeless women. J Clin Nurs 2013;22:1080-93.

156. Wathen $\mathrm{CN}$, MacMillan HL. Interventions for violence against women: scientific review. JAMA 2003;289:589-600.

157. Constantino R, Kim Y, Crane PA. Effects of a social support intervention on health outcomes in residents of a domestic violence shelter: a pilot study. Issues Ment Health Nurs 2005;26:575-90.

158. Gubits D, Shinn M, Wood M, et al. Family options study: 3-year impacts of housing and services interventions for homeless families. 2016. doi: 10.2139/ ssrn.3055295.

159. Milby JB, Schumacher JE, Wallace D, et al. To house or not to house: the effects of providing housing to homeless substance abusers in treatment. Am J Public Health 2005;95:1259-65.

160. Nyamathi AM, Leake B, Flaskerud J, et al. Outcomes of specialized and traditional AIDS counseling programs for impoverished women of color. Res Nurs Health 1993;16:11-21.

161. Nyamathi A, Flaskerud J, Keenan C, et al. Effectiveness of a specialized vs. traditional AIDS education program attended by homeless and drug-addicted women alone or with supportive persons. AIDS Educ Prev 1998;10:433-46.

162. Wang JZ, Mott S, Magwood O, et al. The impact of interventions for youth experiencing homelessness on housing, mental health, substance use, and family cohesion: a systematic review. BMC Public Health 2019;19:1528.

163. Couch J. 'My life just went zig zag': refugee young people and homelessness. Youth Stud Aust 2011;30:22-32.

164. Couch J. 'Neither here nor there': refugee young people and homelessness in Australia. Child Youth Serv Rev 2017;74:1-7.

165. Couch J. On their own: perceptions of services by homeless young refugees. Dev Pract 2012;(31):19-28.

166. D'Addario S, Hiebert D, Sherrell K. Restricted access: The role of social capital in mitigating absolute homelessness among immigrants and refugees in the GVRD. Refuge 2007;24:107-15.

167. Dwyer P, Brown D. Accommodating "others"?: housing dispersed, forced migrants in the UK. J Soc Welf Fam Law 2008;30:203-18.

168. Flatau P, Smith J, Carson G, et al. The housing and homelessness journeys of refugees in Australia. AHURI Final Rep No 256. Melbourne (AU): Australian Housing and Urban Research Institute Limited; 2015.

169. Hulín M, Hulínová VA, Martinkovič M, et al. Housing among persons of international protection in the Slovak Republic. Rajagiri J Soc Dev 2013;5.

170. Idemudia ES, Williams JK, Wyatt GE. Migration challenges among Zimbabwean refugees before, during and post arrival in South Africa. J Inj Violence Res 2013;5:17-27.

171. Im H. A social ecology of stress and coping among homeless refugee families. Vol. 73, Dissertation Abstracts International Section A: Humanities and Social Sciences. University of Minnesota Digital Conservancy; 2012:355. Available: http://ovidsp.ovid.com/ovidweb.cgi?T=JS\&PAGE=reference\&D=psyc9\&NEWS= $\mathrm{N} \& A N=2012-99130-061$ (accessed 2019 Sept. 1). Login required to access content.
172. Kissoon P. From persecution to destitution: a snapshot of asylum seekers' housing and settlement experiences in Canada and the United Kingdom. J Immigr Refug Stud 2010;8:4-31.

173. Kissoon P. An uncertain home: refugee protection, illegal immigration status, and their effects on migrants' housing stability in Vancouver and Toronto. Can Issues 2010;64-7.

174. Mostowska M. Migration and homelessness: the social networks of homeless Poles in Oslo. J Ethn Migr Stud 2013;39:1125-40.

175. Mostowska M. Homelessness abroad: "place utility" in the narratives of the Polish homeless in Brussels. Int Migr 2014;52:118-29.

176. Paradis E, Novac S, Sarty M, et al. Homelessness and housing among status immigrant, non-status migrant, and Canadian-born Families in Toronto. Can Issues 2010.

177. Sherrell K, D'Addario S, Hiebert D. On the outside looking in: the precarious housing situations of successful refugee claimants in the GVRD. Refuge 2007;24:64-75.

178. Sjollema SD, Hordyk S, Walsh CA, et al. Found poetry: finding home - a qualitative study of homeless immigrant women. J Poetry Ther 2012;25:205-17.

179. Walsh CA, Hanley J, Ives N, et al. Exploring the experiences of newcomer women with insecure housing in Montréal Canada. J Int Migr Integr 2016;17: 887-904.

180. Kendall CE, Shoemaker ES, Crowe L, et al. Engagement of people with lived experience in primary care research: living with HIV Innovation Team Community Scholar Program. Can Fam Physician 2017;63:730-1.

181. Swinkels H, Pottie K, Tugwell P, et al.; Canadian Collaboration for Immigrant and Refugee Health (CCIRH). Development of guidelines for recently arrived immigrants and refugees to Canada: Delphi consensus on selecting preventable and treatable conditions. CMAJ 2011;183:E928-32.

182. Guyatt G, Oxman AD, Akl EA, et al. GRADE guidelines: 1. Introduction - GRADE evidence profiles and summary of findings tables. J Clin Epidemiol 2011;64: 383-94.

183. Pottie K, Mathew CM, Mendonca O, et al. PROTOCOL: A comprehensive review of prioritized interventions to improve the health and wellbeing of persons with lived experience of homelessness. Campbell Syst Rev 2019;15:e1048.

184. Magwood O, Gebremeskel A, Ymele Leki V, et al. Protocol 1: The experiences of homeless and vulnerably housed persons around health and social services. A protocol for a systematic review of qualitative studies. Cochrane Methods Equity; 2018. Available: https://methods.cochrane.org/equity/sites/methods.cochrane. org.equity/files/public/uploads/protocol__the_experiences_of_homeless_and_ vulnerably_housed_persons_around_health_and_social_services.pdf (accessed 2019 Dec. 12).

185. Kpade V, Magwood O, Salvalaggio G, et al. Protocol 3: Harm reduction and pharmacotherapeutic interventions for persons with substance use disorders: a protocol for a systematic review of reviews. Cochrane Methods Equity; 2018.

186. Wang J, Mott S, Mathew C, et al. Protocol: Impact of interventions for homeless youth: a narrative review using health, social, Gender, and equity outcomes. Cochrane Methods Equity; 2018. Available: https://methods.cochrane.org/ equity/sites/methods.cochrane.org.equity/files/public/uploads/youth_narrative _review_protocol.pdf (accessed 2019 Dec. 12).

187. Alonso-Coello P, Oxman AD, Moberg J, et al.; GRADE Working Group. GRADE Evidence to Decision (EtD) frameworks: a systematic and transparent approach to making well informed healthcare choices. 2: Clinical practice guidelines. BMJ 2016;353:i2089.

188. Alonso-Coello P, Schünemann HJ, Moberg J, et al.; GRADE Working Group. GRADE Evidence to Decision (EtD) frameworks: a systematic and transparent approach to making well informed healthcare choices. 1: Introduction. BMJ 2016;353:i2016.

189. Schünemann HJ, Mustafa R, Brozek J, et al.; GRADE Working Group. GRADE Guidelines: 16. GRADE evidence to decision frameworks for tests in clinical practice and public health. J Clin Epidemiol 2016;76:89-98.

190. GRADEpro GDT: GRADEpro Guideline Development Tool [software]. Hamilton (ON): McMaster University; 2015 (developed by Evidence Prime, Inc.). Available: https://gradepro.org (accessed 2019 Feb. 1).

191. Tugwell P, Knottnerus JA. When does a good practice statement not justify an evidence based guideline? J Clin Epidemiol 2015;68:477-9.

192. Guyatt GH, Alonso-Coello P, Schünemann HJ, et al. Guideline panels should seldom make good practice statements: guidance from the GRADE Working Group. J Clin Epidemiol 2016;80:3-7.

193. Guyatt GH, Schünemann HJ, Djulbegovic B, et al. Guideline panels should not GRADE good practice statements. J Clin Epidemiol 2015;68:597-600.

194. Drazen JM, de Leeuw PW, Laine C, et al. Toward more uniform conflict disclosures: the updated ICMJE conflict of interest reporting form. JAMA 2010;304:212-3. 
195. Primack RB, Cigliano JA, Parsons ECM, et al. Coauthors gone bad; how to avoid publishing conflict and a proposed agreement for co-author teams [editorial]. Biol Conserv 2014;176:277-80.

196. WHO housing and health guidelines. Geneva: World Health Organization; 2018.

197. Korownyk C, Perry D, Ton J, et al. Managing opioid use disorder in primary care: PEER simplified guideline. Can Fam Physician 2019;65:321-30.

198. Bruneau J, Ahamad K, Goyer M-Ė, et al.; CIHR Canadian Research Initiative in Substance Misuse. Management of opioid use disorders: a national clinical practice guideline. CMAJ 2018;190:E247-57.

199. Fairbairn N, Ross J, Trew M, et al. Injectable opioid agonist treatment for opioid use disorder: a national clinical guideline. CMAJ 2019;191:E1049-56.
200. Montauk SL. The homeless in America: adapting your practice. Am Fam Physician 2006;74:1132-8.

201. Teixeira L, Russell D, Hobbs T. The SHARE framework: a smarter way to end home lessness. London (UK): Centre for Homelessness Impact; 2018; Available: www. homelesshub.ca/resource/share-framework-smarter-way-end-homelessness (accessed 2019 Dec. 12)

202. Purkey E, Patel R, Phillips SP. Trauma-informed care: better care for everyone. Can Fam Physician 2018;64:170-2.

203. Homelessness \& health: What's the connection [fact sheet]. Nashville (TN): National Health Care for the Homeless Council; 2011. Available: https://nhchc.org/wp-content /uploads/2019/08/Hln_health_factsheet_Jan10-1.pdf (accessed 2019 June 1).
Competing interests: Gary Bloch is a founding member, former board member and currently a clinician with Inner City Health Associates (ICHA), a group of physicians working with individuals experiencing homelessness in Toronto, which provided funding for the development of this guideline. He did not receive payment for work on the guideline and did not participate in any ICHA board decision-making relevant to this project. Ritika Goel, Michaela Beder and Stephen Hwang also receive payment for clinical services from ICHA, and did not receive payment for any aspect of the submitted work. No other competing interests were declared.

This article has been peer reviewed.

Affiliations: C.T. Lamont Primary Health Care Research Centre (Pottie, Kendall, Magwood, Shoemaker, Saad, Hannigan, Wang, Kaur), Bruyère Research Institute; Department of Family Medicine (Pottie, Kendall, Ponka, Shoemaker), and School of Epidemiology and Public Health (Pottie, Kendall), University of Ottawa; Ottawa Hospital Research Institute (Kendall, Shoemaker), Ottawa, Ont.; ICES (Kendall, Shoemaker); Li Ka Shing Knowledge Institute (Kendall), St. Michael's Hospital, Toronto, Ont.; School of Psychology (Aubry), University of Ottawa, Ottawa, Ont.; Departments of Family Medicine, and Epidemiology, Biostatistics and Occupational Health (Andermann), Faculty of Medicine, McGill University, Montréal, Que.; Department of Family Medicine (Salvalaggio), Faculty of Medicine and Dentistry, University of Alberta, Edmonton, Alta.; Besrour Centre for Global Family Medicine (Ponka), College of Family Physicians of Canada, Mississauga, Ont.; Department of Family and Community Medicine (Bloch), St. Michael's Hospital; Department of Family and Community Medicine (Bloch), Faculty of Medicine, University of Toronto; Inner City Health Associates (Bloch, Bond, Hwang, Goel), Toronto, Ont.; Department of Family Practice (Brcic), University of British Columbia, Vancouver, BC; Department of Pediatrics, Obstetrics and Gynecology and Preventive Medicine and Public Health (Agbata), Faculty of Medicine, Universitat Autònoma de Barcelona; Ottawa Hospital Research Institute (Thavorn); School of Epidemiology and Public Health (Thavorn), University of Ottawa; Bruyère Research Institute (Mathew), Ottawa, Ont.; Department of Family and Community Medicine (Bond, Goel), University of Toronto, Toronto, Ont.; Faculty of Medicine (Crouse), Memorial University, St. John's, NL; Department of Family Medicine (Crouse), Dalhousie University, Halifax, NS; Faculty of Medicine (Wang, Kaur, Hashmi), University of Ottawa, Ottawa, Ont.; Department of Family Medicine (Mott), McGill University, Montréal, Que.; Department of Health Research Methods, Evidence, and Impact (Piggott, Guenter), McMaster University, Hamilton, Ont.; scholar in residence (Arya), Wilfrid Laurier University, Waterloo, Ont.; Department of Family Medicine (Arya), McMaster University, Hamilton, Ont.; Centre for Addiction and Mental Health (Kozloff, Stergiopoulos); Department of Psychiatry, and Institute of Health Policy, Management and Evaluation (Kozloff), University of Toronto; Department of Psychiatry (Beder), University of Toronto and St. Michael's Hospital, Toronto, Ont.; Department of Family Medicine (Guenter), McMaster University, Hamilton, Ont.; Ottawa Inner City
Health (Muckle), Ottawa, Ont.; MAP Centre for Urban Health Solutions (Hwang), St. Michael's Hospital, Toronto, Ont.; Department of Medicine (Tugwell), University of Ottawa, Ottawa, Ont.

Contributors: Kevin Pottie, Claire Kendall, Peter Tugwell, Tim Aubry, Vicky Stergiopoulos, Olivia Magwood, Anne Andermann, Ginetta Salvalaggio, David Ponka, Gary Bloch, Vanessa Brcic and Eric Agbata contributed substantially to the study concept and design. Kednapa Thavorn led the medico-economic analysis. Andrew Bond, Susan Crouse, Ritika Goel, Dale Gunter, Terry Hannigan and Wendy Muckle led the Homeless Health Summit. Esther Shoemaker led the Delphi consensus. Olivia Magwood led the reviews on lived experiences and substance use, Tim Aubry led the review on housing, Gary Bloch and Vanessa Brcic led the review on income, David Ponka and Eric Agbata led the review on case management, Jean Zhuo Jing Wang and Sebastian Mott led the homeless youth review, Harneel Kaur led the homeless migrant review, Christine Mathew and Anne Andermann led the homeless women review, Syeda Shanza Hashmi and Ammar Saad led medical student engagement and competency review, Thomas Piggott co-led the GRADE Assessment with Olivia Magwood and Kevin Pottie, Michaela Beder and Nicole Kozloff contributed substantially to the substance use review, and Neil Arya and Stephen Hwang provided critical policy information. All of the named authors engaged in the writing and review, gave final approval of the version of the guideline to be published, and agreed to be accountable for all aspects of the work.

Funding: This guideline was supported by a peer-reviewed grant from the Inner City Health Associates, and supplemental project grants from the Public Health Agency of Canada, Employment Social Development Canada, Canadian Medical Association and Champlain Local Integrated Health Network. Personnel from collaborating agencies provided nonbinding feedback during the preparation of systematic reviews and the guideline. The funders had no role in the design or conduct of the study; collection, analysis and interpretation of the data; or preparation, review or final approval of the guideline. Final decisions regarding the protocol and issues that arose during the guideline-development process were solely the responsibility of the guideline steering committee.

Acknowledgements: The authors thank everyone who participated in the development of this guideline, including community scholars, technical team leads, guideline panel members and working group members.

Endorsements: Canadian Medical Association, Canadian Public Health Association, Canadian Federation of Medical Students, The College of Family Physicians of Canada, Public Health Physicians of Canada, Canadian Association of Emergency Physicians, The Canadian Alliance to End Homelessness, Canadian Nurses Association

Disclaimer: The views expressed herein do not necessarily represent the views of the funding agencies.

Correspondence to: Kevin Pottie, kpottie@uottawa.ca 